\title{
Analysis Of The Factors Influencing Household Expenditure In A South African Township
}

T.J. Sekhampu, North-West University, South Africa

F. Niyimbanira, Vaal University of Technology, South Africa

\begin{abstract}
The study reported in this article examined the socio-economic determinants of household expenditure patterns in a South African township of Bophelong. The results are based on a household survey using questionnaires. A multiple regression model was used to explain responses in monthly expenditures to socio-economic factors. Household income, household size, the number of people who are employed, employment status, and the educational attainment of the household head were found to exert a strong positive impact on household expenditure. The marital status of the household head was associated with a negative impact on household expenditure. The gender and age of the household head had no impact on the variations in household expenditure. The results of this study contribute to the understanding of township residents by analysing the socio-economic factors associated with household expenditure.
\end{abstract}

Keywords: Household Expenditure; Determinants; Regression; Township; South Africa

\section{INTRODUCTION}

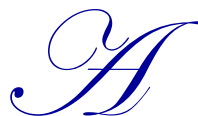

n analysis of household consumption patterns has become topical due to the impact of household decisions on economic development and policy planning purposes (Deaton, Ruiz-Castillo \& Thomas, 1980). Many studies have been undertaken over the last two or three decades and from them, much has been learnt in both developed and developing countries (Thomas, 1990). A number of approaches have been used to quantify the role of household composition in determining household food expenditures. Grossman (1972a, 1972b) emphasises the importance of education and income in household decision making. Other studies have found the age of the household head to be an important predictor of household expenditure (Muurinen, 1982; Wagstaff, 1986; Bohlin et al, 1999). Most studies undertaken on developed countries use an annual income as a proxy for a household's economic situation. However, household consumption could be a better approximation of economic circumstances, especially in developing countries where annual income is erratic and inconsistent. There is little theoretical and empirical research on consumer behaviour regarding household consumption patterns in South Africa townships. Hence, the purpose of this study is to fill this gap. According to Maitra and Ray (2002), households in South Africa, particularly township residents, have long been dependent on income transfers from members working away from home in mines, factories and plantations. Another source of income is from the universal social pension scheme provided by the national government. Common studies about expenditure patterns of households in South Africa are mainly based on national studies. A study by Balyamujura et al. (2000) cites that increasing strain on food expenditure brought about the impact of HIV/AIDS. Another study by Oyewumi and Jooste (2006) on pork consumption in Bloemfontein (South Africa) found income as an important determinant. Dunne and Edkins (2005) studied the demand for food in South Africa and concluded that an increase in price will lead to a more-than-proportionate decline in demand.

This study analyzed household expenditure patterns in a complete systems framework where the possible endogeniety of source of income flows into the household is taken into account in the estimation. The main objective of this study was to identify and quantify the relationship between household expenditure and the socio- 
economic and demographic characteristics of the household. The findings of the study are important to efforts in understanding the factors that influence household expenditure in a South African township. A formerly blacks only township in South Africa provides an ample case study. South Africa's historical circumstances have shaped the present configuration of poverty and opportunities along racial lines. Disadvantaged groups were systematically left with relatively little in the way of land and other resources, were not afforded education of quality comparable to that of whites, and were compelled to adopt coping strategies. A random sample of households was surveyed in a township called Bophelong. Bophelong is an urban township established in 1955 on the outskirts of the industrial town of Vanderbijlpark as a dormitory township for cheap black labour for surrounding industries. The area belongs to the Emfuleni Municipality on the southern part of the Gauteng Province in South Africa. The heart of Bophelong remains in the old township where a few amenities exist - a clinic, a library, council offices, a satellite police station and a few local shops. The population in Bophelong is estimated at 37,779 and the number of households is estimated at 12,352 . Previous studies have found seemingly high poverty levels in the area where $67 \%$ of the households were found to be living below their poverty lines in 2003 (Slabbert, 2003). A study by Slabbert (2009) revealed increasing levels of poverty where $69 \%$ of the sampled population in Bophelong was found to be poor. A multiple regression model was used to determine the socio-economic factors affecting monthly total household expenditure.

\section{RESEARCH METHODOLOGY}

The data for this study were collected in Bophelong during March 2012. A total of 600 questionnaires were randomly administered in the area through face-to-face interviews. The questionnaire included information on demographics, respondents' income and expenditure patterns, and their general view about their socio-economic status. In total, data from 579 households were deemed legible for the purpose of this study. The selection of variables likely to influence household expenditure relies on previous studies by Steward et al. (2004), McCracken and Brandt (1987), and Redman (1980). The data were analyzed using Statistical Package for the Social Sciences (SPSS). A multiple regression model was used to determine the socio-economic and demographic factors affecting household expenditure. The regression model was estimated as follows:

$$
Y_{t}=\beta_{0}+\beta_{1} x_{1}+\beta_{2} x_{2}+\beta_{3} x_{3} \ldots \ell_{t}
$$

where $Y_{t}$ is the dependent variable, unobserved, while $X_{t}$ is vector of explanatory variables, $\beta_{0}$ is the vector of unknown parameters (Intercept), and $\ell_{\mathrm{t}}$ is the error term. The following socio-demographic characteristics are therefore hypothesized to influence total household expenditure: $\beta_{1}$ total monthly household income recorded in Rands, $\beta_{2}$ household size, $\beta_{3}$ education attainment of the household head, $\beta_{4}$ gender, $\beta_{5}$ age $\beta_{6}$, marital status, $\beta_{7}$ employment status of household head, and $\beta_{8}$ the number of people who are employed.

\section{FINDINGS AND DISCUSSIONS}

\section{Demographic Characteristics of the Respondents}

The descriptive statistics for the sampled population show that the youngest head of household was 18 years, with the oldest being 90 years old. The number of persons per household varied from 1 to 13 . The average household had four members. There were greater variations in household income, with the lowest recorded at R100 per month and the highest at R18000. Household income is the total income earned/received by the various household members. The results also showed that $49.4 \%$ of households were headed by females (G_Head). The average number of years of schooling of the respondents (Educ_Head) was 6.21 years, which equates to primary schooling education. An analysis of the marital status of the respondents shows that $47.2 \%$ were married. Regarding the employment status of the respondents; $58.1 \%$ were not employed. The lowest monthly expenditure was R190 and the highest at R9882 per month. The monthly average total expenditure was recorded at R1658. 


\section{Categories of Household Expenditure}

Households spend their income on different types of goods and services. Figure 1 shows the breakdown of household expenditure in percentages. The total average household expenditure was recorded at R1658.41 per month. Food represented the single largest expense, accounting for $45.5 \%$ of total monthly expenses. The next biggest single item is energy expenses at $9.8 \%$; major energy types used by households are electricity, coal and paraffin. Other items are: Insurance - 8.3\%, household debt - 7.8\%, transport - 7.2\%, housekeeping - 4.6\%, and other expenses $-12.6 \%$. The form of insurance recorded from households is a funeral scheme where a household makes a monthly contribution to a funeral undertaker and will receive burial benefits (coffin, hearse, etc.) upon the death of the insured, along with a small cash amount for funeral expenses as shown in Figure 1.

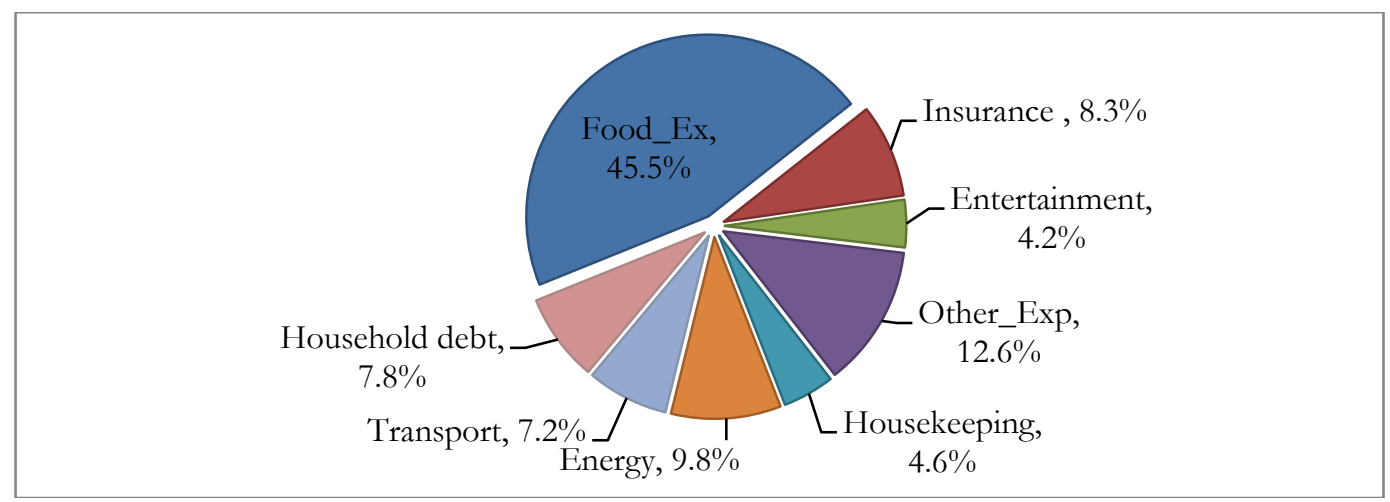

Figure 1: Categories of Household Expenditure

\section{Sources of Household Income}

The respondents were asked about the sources of household income. Market income in the form of salaries and wages contributes $50.5 \%$ to household income. The state's old-age pension grant (SOAPG) is the second highest contributor to household income at $19.2 \%$. The state's old age grant is means tested and given to South African residents who are older than 60 years and in need. Other contributors are the child support grant (CSG), which is given to parents of children younger than 18 years and in need, that contributes, on average, $6.2 \%$ to household income; other government grants (OGG), which includes the disability grant, foster-care grant (10.9\%), help (5.3\%), and informal activities (7.8\%). If added together, government grants, on average, make up 36.3\% of household income. The average household income was calculated at R1825.25 per month.

\section{Socio-economic Determinants of Household Expenditure}

The results of the regression model on the factors that affect household expenditure are shown in Table 1. The results of the survey show that household income (HH_Income), household size (HH_Size), the number of people employed (Employed_NP), employment status (ES_Head), and the educational attainment of the household head (Educ_Head) significantly influence household expenditure. These variables were found to exert a positive impact on household expenditure, whereas the marital status of the head of household is negatively associated with household expenditure. The coefficient for the variable (MS_Head -.098) was significant at $1 \%$. 
Table 1: Regression Analysis of Determinants of Household Expenditure

\begin{tabular}{|l|c|c|c|c|c|}
\hline & Coef. & Std. Err. & T & P>|t| & ey/ex \\
\hline HH_Income & 0.246427 & 0.015912 & 15.49 & $0 *$ & 0.317663 \\
\hline G_Head & 44.1101 & 93.5763 & 0.47 & 0.638 & 0.016033 \\
\hline HH_Size & 60.75939 & 24.51258 & 2.48 & $0.013^{*}$ & 0.165918 \\
\hline MS_Head & -258.972 & 94.23815 & -2.75 & $0.006^{*}$ & -0.09354 \\
\hline Educ_Head & 34.18076 & 10.9935 & 3.11 & $0.002^{*}$ & 0.146164 \\
\hline ES_Head & 292.3305 & 102.8655 & 2.84 & $0.005^{*}$ & 0.067429 \\
\hline Age_Head & 5.063842 & 3.430978 & 1.48 & 0.141 & 0.175034 \\
\hline Employed_NP & 134.3593 & 68.91457 & 1.95 & $0.052^{*}$ & 0.124486 \\
\hline cons & 112.234 & 225.3709 & 0.5 & 0.619 & \\
\hline$R^{2}=.406$ *significant at the 1\% level.
\end{tabular}

For this model, household income (HH_Income), $\mathrm{t}(579)=15.49$, and the educational attainment of the head of household (Educ_Head), t $(579)=3.11 \mathrm{p}<.01$, are significant predictors of household expenditure. The gender (G_Head) and age (Age_Head) of the head of household were not important in explaining the variations in household expenditure. The statistical non-significance of these coefficients suggests that these variables are not important factors with regard to explaining household expenditure patterns. The model containing all explanatory variables was significant, indicating that the model was able to distinguish between the various explanatory variables used in the model. The regression model, as a whole, explained $40.6 \%\left(\mathrm{R}^{2}=.406\right)$ of the variations in all cases. The Durbin-Watson test is another measure of model adequacy. This statistic informs us as to whether the assumption of independent errors is tenable. The closer to 2 the value is, the better, and for these data, the value is 1.66. The F-ratio for the model was calculated at 48.67 , which is also highly significant ( $\mathrm{p}<.001$ ).

\section{DISCUSSION AND CONCLUSION}

This study analyzed the expenditure patterns of households in a South African township of Bophelong. A multiple regression model was used to determine the factors influencing household expenditure. Data from a random sample of 579 households in Bophelong was analyzed, with the monthly household expenditure as the dependent variable and a number of socio-economic characteristics as explanatory variables. The total average household expenditure was recorded at R1658.41 per month. Food represented the single largest expense, accounting for 45.5\% of total monthly expenses. The next biggest single item is energy expenses at $9.8 \%$. The respondents were also found to be repaying household debt (7.8\% of household expenditure). An analysis of the sources of household income shows that salaries and wages make the most contribution (50.5\%) to household income. The various government grants given to those in need and qualifying contributes about $36.3 \%$ to household income.

The results of the regression analysis on the factors influencing household expenditure suggest that household income, household size, the number of people employed, employment status, marital status, and the educational attainment of the household head significantly affect total monthly expenditure. Specifically, as household income increases, total monthly expenditure is expected to increase. A percentage increase in household income was associated with a $32 \%$ increase in total household expenditure. Household income is important as it determines how much can be spent on various needs of the household. The quantity and quality of a household's expenditure patterns are highly correlated with the purchasing power of the household. Larger households are also associated with increased expenditure. In elasticity terms, a one percentage increase in household size will lead to a $17 \%$ increase in household expenditure. It was expected that household size would significantly impact household expenditure. These results are consistent with those of Davis et al. (1983) who concluded that household income and household size exert a significant positive impact on household expenditure. The number of people employed, employment status, and the educational attainment of the household head were also associated with a positive influence on household expenditure. This suggests that households where the head has more education, they have higher household expenditure than their less educated counterparts. A percentage increase in the educational attainment of the head of household was associated with a $15 \%$ increase in household expenditure. Individuals with different levels of education may have other knowledge and different perceptions about diet and health, and consequently may have a different consumption basket. An increase in the number of people employed was associated with an increase in income. An analysis of the elasticity reveals that a $1 \%$ increase in the number of people employed will lead to a $12 \%$ increase in total household expenditure. The marital status of the respondents 
was negatively associated with household expenditure. The negative parameter indicates that with other variables constant, household expenditure for married respondents is relatively less than their unmarried counterparts. Married household heads might benefit from efficiencies in food purchasing brought by joint decision-making. Of the total sample, $47.2 \%$ of respondents were married.

The gender and age of the head of household were not important in explaining the variations in household expenditure. These findings go against a well held tenet that younger and older people have differences in tastes and preferences for food, eating habits, and lifestyles. The mean age of the sample was 48, with a standard deviation of 14. The results reported here contribute to a growing body of empirical evidence in South Africa, suggesting that socio-economic and demographic characteristics must be considered as important predictors of the expenditure patterns of township residents. This study can act as a reference source when setting policies relating to urban dwellers in South Africa.

\section{AUTHOR INFORMATION}

T.J. Sekhampu is a Senior Lecturer in Economics at North-West University, South Africa. His research interest is in poverty and socio-economic studies. E-mail: joseph.sekhampu@nwu.ac.za (Corresponding author)

Ferdinand Niyimbanira is currently a Lecturer in Economics at Vaal University of Technology (VUT), South Africa. His research interest is on econometrics and development studies. E-mail: ferdinandm@vut.ac.za

\section{REFERENCES}

1. Balyamujura, H., Jooste, H., Van Schalkwyk, H., \& Carstens, J. (2000). Impact of the HIV/AIDS Pandemic on the Demand for Food in South Africa. Paper presented at The Demographic Impact of HIV/AIDS in South Africa and its Provinces, East Cape Training Centre. Port Elizabeth.

2. Bohlin K, Jacobson L, Lindgren B. (1999). The family as the health producer - When spouses are Nashbargainers. Studies in Health Economics 30, Department of Community Medicine, Lund University, Lund.

3. Deaton, A., Ruiz-Castillo, J. and Thomas, D. (1980). The Influence of Household Composition on Household Expenditure Patterns: Theory and Spanish Evidence. Journal of Political Economy, 97, 1, 179200.

4. Davis, C. G., Moussie, M., Dinning, J. S., \& Chistakis, G. J. (1983). Socioeconomic determinants of food expenditure patterns among racially different low-income households: an empirical analysis. Western Journal of Agricultural Economics, 8(2), 183-196.

5. Dunne, J., \& Edkins, B. (2005). The demand for food in South Africa. Economics Society South Africa Conference, September. Durban.

6. Grossman, M (1972a). On concept of health capital and the demand for health. Journal of Political economy, 80, March-April, 223-255.

7. Grossman, M (1972b). The demand for health: A Theoretical and empirical investigation. New York, Columbia university press (for NBER).

8. Maitra, P \& Ray, R (2003). The effect of transfers on household expenditure patterns and poverty in South Africa. Journal of Development Economics, vol. 71(1), 23-49.

9. McCracken, V., \& Brandt, J. (1987). Household Consumption of Food Away from Home: total expenditure and by type of food facility. American Journal of Agricultural Economics, 69, 274-284.

10. Muurinen, J. M. (1982). Demand for health: A generalised Grossman model. Journal of Economics 1, 5-28.

11. Oyewumi, O. A., \& Jooste, A. (2006). Measuring the determinants of pork consumption in Bloemfontein, Central South Africa. Agrekon, 42(2), 185-197.

12. Redman, B. (1980). The Impact of Women's Time Allocation on Expenditure for Meals Away From Home and Prepared Foods. American Journal of Agricultural Economics, 62, 234-237.

13. Slabbert, T. (2003). Bophelong: a socio-economic \& environmental analysis. Vanderbijlpark: Vaal Research Group.

14. Slabbert, T. (2009). Bophelong: a socio-economic \& environmental analysis. Vanderbijlpark: Vaal Research Group. 
15. Steward, H., Blisard, N., Byuyan, S., \& Nayga, R. (2004). The Demand for Food from Home: Full-Service or Fast Food. Retrieved June 10, 2012, from www.ers.usda.gov/publications/aer-agricultural.../aer829.aspx

16. Thomas, D. (1990). Intra-Household Resource Allocation: An Inferential Approach. Journal of Human Resources, Fall, 1990, 25, 4, 635-664.

17. Wagstaff, A. (1986). The demand for health: Some new empirical evidence. Journal of Health Economics 5, 195-233. 